\title{
Accounting Control, Governance and Anti-Corruption Initiatives in Public Sector Organisations
}

\begin{abstract}
This special issue focuses on the interactions between accounting, public sector organisations and the socio-economic and political environments in which they operate, with a specific focus on the critical analysis of policy and practice in the fight against corruption. The aim of the special issue is to disseminate knowledge to enable a more sustainable, accountable and less corrupt public sector, regardless of where it is located in the world. It presents the work of a global community of scholars engaged in research projects on policies and strategies related to accountability, transparency, auditing, regulatory disclosure, governance, investor protection and anti-corruption initiatives in public sector organisations. The papers presented here address many different angles of corruption and aspects of the way in which it is reported using a broad range of methodologies, theoretical frameworks and research locations. Collectively, these papers demonstrate that more attention needs be given to investigating the human cost associated with illegal activity that leads to human suffering, inequality, and lifetime costs. They further emphasise that we have much to learn about regulatory disclosure and jurisprudential practice in the fight against fraud and corruption.
\end{abstract}

\section{Introduction}

The effects of corruption are not just a moral concern or matter of principal. Rather, corruption has far reaching consequences for government and society, particularly those segments of society that are most vulnerable; the weak and poor (Quah, 2001). World corruption data produced by the World Bank in 2017, estimates that $\$ 1.5$ trillion is paid in bribes, while the World Economic Forum (2017) argues that it is closer to $\$ 2.6$ trillion, which equates to more than 5\% of global GDP. Systemic corruption is a major obstacle to economic and political development in any country where it prevails. Corruption undermines economic development, political stability, incentives to investors, and generates distrust (Rothstein \& Varraich, 2017). Tackling these issues should be a priority for governments in both developed and developing countries.

In the quest to fight systematic corruption, governments in both developed and developing countries have over the years, undertaken numerous public financial management reforms that focus on enhancing financial controls, financial reporting, transparency, accountability and governance within their public-sector organisations. A key component within this public sector reform world-wide has been the introduction of new public management (NPM), within which accounting is considered to play a central role in the monitoring and control of resources through its auditing and regulatory disclosure functions. In recent years, substantial research has taken place into the way that many Western countries have used such practices to achieve centralisation of public services, alongside the increased involvement of the private sector. Less attention has been paid to the work of some developing countries on the decentralization of responsibility for public sector services; that is the transfer of power and responsibility for public services from central government to independent or semi-autonomous regional and local governments. Therefore, our understanding of what works in different contexts, and the 
interactions and interdependencies between different policy interventions, is undeveloped. Consequently, research into the design and implementation of policies that have the most impact on reducing corruption is needed.

The principal aim of commissioning this special issue was to engage a global community of scholars in research projects on policies and strategies related to accounting control, accountability, governance and anti-corruption initiatives in public sector organisations and to disseminate knowledge to enable a more sustainable, accountable and less corrupt public sector, regardless of where it is located in the world. Thus, the papers presented within this special issue address many different angles of corruption using a broad range of methodologies, theoretical frameworks and research locations. Our discussion begins with the key components of NPM and decentralisation. Following this the role accounting can play in increasing accountability and transparency through auditing and regulatory disclosure to reduce corruption is presented. The effectiveness of institutional governance and investor protection initiatives are then put forward. The final paper of this special issue considers the implications of recent European reform that introduces calculative practices that account for crime.

\section{Accounting Control}

Implicit key components of NPM include the disaggregation of units; decentralisation of managerial responsibilities and functions resulting in devolved budgetary systems and financial responsibility/accountability (Farnham and Horton, 1996) combined with increasing use of contracting out and other market type mechanisms which rely on third party agents. These third-party agents work with government agencies and each other, thus forming a fluctuating network that holds discretion over the management and use of public funds (Salamon, 2002). However, von Maravic (2007) argues that while NPM has empowered public sector managers, the decentralisation of managerial and financial responsibilities introduces greater risk of conflicts of interest and opportunities for corruption.

A body of prior research acknowledges that NPM mechanisms are interrelated and interlinked (Hood, 1991; Pollitt, 1995) and that weak financial accounting and reporting systems can stifle citizens' monitoring incentives, thereby reducing decentralization benefits (Bardhan, 2002; World Bank, 2001). However, most studies have separately examined both the relationship between accounting practice and corruption and the relationship between corruption and decentralization. There has been little research to date that considers the combined roles of accounting practice and decentralization on corruption, or whether they complement each other in reducing corruption.

The paper by Changwony and Paterson aims to fill this gap and stands at the intersection between the accounting and decentralization strands of the corruption literature. Their paper is motivated by, and builds upon, three strands of literature. First, it builds upon the literature on the relationship between accounting practice and corruption. Second, it contributes to a broad range of literature on the relationship between decentralization and corruption. Third, it extends a nascent but growing body of literature that questions the implicit assumption that there is a direct relationship between decentralization and corruption. A novel contribution of the paper, therefore, concerns this plausible connection between the hitherto separate accounting and decentralization literatures on corruption. The authors further examine whether the quality of 
accounting practice can influence the relationship between decentralization and corruption using a cross-section of data of 128 countries and multiple data sources. The study findings reveal that the information function of accounting is critical for improving the effectiveness of decentralization monitoring mechanisms, as it reduces information asymmetry between political actors and voters at local levels, and thus increases political accountability and reduces corruption. These findings are important as they suggest that supranational organisations and governments need to pay more attention to strengthening the quality of financial reporting standards in order to exploit the benefits of decentralization in reducing corruption.

\section{Auditing and Regulatory Disclosure}

Another prominent theme surrounding the debate concerning anti-fraud and corruption policy is the role accounting can play in increasing accountability and transparency through auditing and regulatory disclosure. Accountability and transparency are deemed important in the prevention of public sector corruption and fraudulent activity together with effective auditing which is considered to help minimise the misrepresentation of accounting information and thus provide some assurance as to the validity of the accounts (Dye, 2007). Supreme Audit Institutions (SAI's) are considered key in the fight against fraudulent and corrupt activity with institutions such as the World Bank, and the OECD calling for SAIs and the International Organisation of Supreme Audit Institution (INTOSAI) to take a more proactive role against fraud and corruption (Borge, 1999; Dye, 2007). In response SAIs and the INTOSAI have contributed to the production and implementation of numerous auditing guidelines, standards and frameworks which seek to foster good governance and has enabled them to build up and assume considerable levels of legitimacy. However, despite this, SAIs generally appear reluctant to take a comprehensive role in the fight against corrupt and fraudulent behaviour, limiting their role to corruption prevention through audits rather than corruption detection (Kayrak, 2008).

Reichborn-Kjennerud et al. (this issue), using an institutional approach and data on seven SAIs from Scandinavia, South-European and African countries, investigate how SAIs perceive their responsibilities in the fight against corruption. This takes place in the context of an unclear mandate and increasing institutional and stakeholder pressures. Their data analysis revealed mimetic, coercive and normative pressures to fight corruption. With regards to the mimetic pressure in tackling fraud and corruption, this was shown to be limited by institutional logics and cultural and political norms. Likewise, the effectiveness of coercive measures operationalised through institutional legal frameworks varied. SAIs in more corrupt environments were not explicitly shown to engage more in anti-corruption practices hence the level of corruption, as a single indicator, is not sufficient to gauge the effectiveness of the SAI's anti-corruption work. Normative pressures to fight corruption were identified as being mainly developed through professional institutional logics. However, a separation between the audit institutions' responsibilities and the prosecutorial and law enforcement institutions was identified. The authors therefore demonstrate that no one single approach alone can curb fraudulent or corrupt behaviour. With respect to the effectiveness of INTOSAI this was also found to be limited. These are important findings that signify that regulatory institutions need to collaborate in the fight against fraud and corruption to achieve systems that are appropriate to both developed and developing economies. Indeed, if INTOSAI is to effectively harmonize 
SAIs' worldwide fight against corruption, increased institutional recognition and collaboration is required.

This view is also reflected in the work of Jeppesen (in this issue) in his investigation into the role of auditing in the fight against corruption at a micro level. Jeppesen begins by outlining how auditing, in theory, has the potential to both prevent and detect fraudulent and corrupt activity. Resistance from the auditing profession and its arguments against an acceptance of responsibility for fraud and corruption within the audit function is also discussed. In an analysis of prior literature, he highlights that private sector financial auditing has largely ignored corruption as a possible source of material errors within financial statements. This is attributed to financial auditing excluding corruption from the definition of fraud and classifying it as 'non-compliance' on the grounds that it leaves no trace or material errors for the auditor to follow. The author contests this view arguing that for most commercial forms of corruption, which entail exchanges of tangible assets, some evidence may exist for the auditor to investigate.

In contrast, Jeppeson finds that public sector auditing accepts a degree of responsibility for the prevention of corruption and takes some steps to identify and mitigate corrupt or fraudulent activity. Notably, the effectiveness of auditing in fraud and corruption detection is constrained by the profession's preference for prevention over detection which is also reflected in ISSA15700 that states "it is much better to prevent than detect corruption" (INTOSAI, 2013:7). This is further complicated by corruption being excluded from ISA 240 which categorizes fraud into two types with no reference to corruption: asset misappropriation and fraudulent financial statements. The findings of this paper therefore have important implications for practice: financial auditors are expected to identify and report material misstatements. As corruption can lead to financial misstatements, it is reasonable to expect auditors to accept responsibility for fraud and corruption detection. Excluding corruption from the definition of fraud in ISA240 results in auditors ignoring the risk of corruption in their audit plans. As such, it is suggested that regulators need to reconsider their definition of what constitutes fraudulent and corrupt activity.

It has been argued that in the regulation and control of fraud and corruption effective punishments and enforcement regimes are essential and should outweigh any financial gains from fraudulent or corrupt behaviour (Werden, 2009; Steinway, 2014). The publication (naming and shaming) of punishments levied against organisations for fraudulent behaviour can have negative effects on public and investor perceptions of the organisation. Likewise, monetary punishments such as fines which are made public can invoke public disapproval, loss of confidence and may have a significant impact on shareholder wealth. For regulators, the publishing of punishments (both monetary and non-monetary) can augment and strengthen the legitimacy of regulation. For organisations subjected to punishment this may increase their willingness to invest in 'beyond-compliance' behaviour (Parker, 2006). As such, regulatory disclosure has featured highly in the drive towards reducing organisational fraud and corruption behaviour and is considered essential in the provision of broader and improved accountability to stakeholders. However, accounting reports and increased disclosure do not provide a comprehensive system that mitigates against dubious or fraudulent behaviour in all contexts.

For example, the paper by Ejiou, Ejiou and Ambituuni (below) challenges the underlying assumption, of the Extractive Industries Transparency Initiative (EITI), that transparency in the 
form of increased information disclosure can lead to enhanced accountability and reduce corruption. Their study draws on a range of data sources related to the Nigerian Extractive Industries including NEITI audit reports and documents relating to the development and implementation of the global EITI framework. It also draws on the IASB conceptual framework for financial reporting to develop an understanding of what constitutes information. Theoretical insights are drawn from the transparency literature which considers transparency as both information disclosure and as a social process. Their analysis of the data provides insights into how increased information disclosure obscures and legitimises the somewhat weak and corrupt reporting systems and practices of government agencies. The authors attribute this to the initiatives being translated to fit the local context and systems, with little consideration being given to how the information is produced, the lack of understandability of the information presented and the influence of local power struggles. Transparency in NEITI is also shown to be a complex social process that is affected by the political will of the government in power. As such their study highlights the need for further investigation into EITI adoption in resource rich countries and the processes through which they are adopted and implemented in local contexts.

In a similar vein, the paper by Mulcahy et al. investigates powers awarded to the Irish Financial Services Ombudsman (FSO) in 2013, to increase regulatory disclosure and 'name and shame' those that regularly engage in financial malfeasance in that country. Prior to the global financial crisis of 2007, and the bank bailout in 2008, regulatory disclosure, accountability and transparency of financial services providers (FSPs) was relatively weak, which gave rise to the perception that systems within public sector organisations had failed to prevent or, in some cases, facilitated financial malfeasance. Likewise, the ability of the FSO to deal with, and resolve complaints against FSPs was considered ineffective. The introduction of the regulatory disclosure and name and shame policy is shown within the Irish context to have had positive effects in reducing the number of complaints and disputes lodged to the FSO as FSPs seek to resolve complaints internally to avoid being named and shamed. The reduction in complaints to the FSO has allowed public sector case managers to focus more time and attention on resolving complex cases. Drawing on neo-Durkheimian institutional theory and the accountability literature, the authors indicate that regulatory disclosure can have considerable impact and emphasise the importance of considering the cultural context in the operationalisation of regulatory disclosure as an accountability mechanism.

In the Chinese context, Wang, Ashton and Jaafar investigate the impact of different punishments (both monetary and non-monetary) for accounting fraud on shareholder valuation. Their findings also emphasise the importance of cultural context when setting and evaluating regulation, as corporate ownership structures vary across the world. For example, in contrast to the US or UK, Chinese listed companies have a highly concentrated ownership structure, often with a single owner holding control. As such, punishment for fraudulent or corrupt behaviour can have a more focussed impact. In their investigation and analysis of Chinese accounting fraud on shareholder valuation between 2007 and 2016 all punishments were noted to have a negative and significant impact on shareholders wealth and investor perceptions. However, monetary punishments were identified as being more effective than non-monetary (naming and shaming) approaches on stock market reactions, particularly if there was an information leakage prior to the announcement of the punishment. This is a useful and important finding for policy makers seeking to understand the effectiveness of such 
punishments on stock market reactions within developing economies with similarly concentrated ownership structures.

\section{Governance, Investor Protection and Accounting for Crime}

In recent years investor protection has attracted the attention of both policy-makers and academics. A central feature of this attention has been a focus on the quality of institutional governance to promote investor protection and improve stock market performance. However, this attention has tended to focus on the firm level (Power, Lonie and Lonie, 1991, Wang 2008, Cornell, Hsu and Nanigian, 2017), which has led to questions being raised as to the relevance of the quality of governance (accountability, level of corruption and government effectiveness) in conditions of economic globalisation. The global financial crisis has further fuelled debate about whether the quality of governance plays a key role in influencing the international financial system. Indeed, it is generally recognised that weak or unacceptable governance quality hampers financial developments and economic growth (Kaufman, Kraay and Mastruzzi, 2009). However, despite this recognition research into the impact of quality governance mechanisms on investor protection in a country level context is still relatively rare.

Sherif and Chen's paper contributes to closing this gap with their investigation into the relationship between global governance indicators and share buying strategies at a countrylevel. They examine the presence of momentum (sell past losers and buy past winners) in a cross-country sample which contains World Bank data on the US, Canada, the UK, Germany, France and Japan. Their study specifically focuses on the relationship between institutional governance factors and abnormal momentum stock returns. Their analysis reveals that accountability and the level of corruption is significantly correlated with government effectiveness. The authors further show that countries and institutional settings with higher scores on accountability and control are likely to be more efficient and effective in providing public and institutional services. As such, their findings are important for practice. Their results suggest that governance quality has a significant effect on transaction costs, which in turn impacts on investor and shareholder wealth, thus meriting policy attention in countries with weaker governance structures. They further offer insights into the complex relationship between institutional governance factors and momentum stock returns, which will be of interest and benefit to regulators seeking to minimise potential future conflicts.

Another investment area that has attracted attention is research and development (R\&D). Investments into $R \& D$ are essential for organisations competing in continuously evolving markets and have a long-term effect on earnings, enable growth, sustainability and value creation (Chan, Lakonishok \& Sougiannis, 2001; Duqi, Jaafar \& Torluccio, 2015). However, the treatment of R\&D has been a contentious issue from academic, standard setting and practitioner perspectives. Within the International Financial Reporting Standards (IFRS) the capitalisation of development costs is laid out in International Accounting Standard 38 Intangible Assets (IAS38). This standard sets down the conditions under which development costs must be capitalised. The application and conditions contained within IAS38 requires managers to make discretionary decisions on the capitalisation of development costs. This provides managers with opportunities to send positive signals about future earnings, which may be distorted by their capitalisation decision, and thus opens up the possibility of corrupt or questionable behaviour. 
Mazzi et al. (below), motivated by prior literatures, hypothesise that in countries with high levels of corruption, managers can take advantage of the corrupt environment and capitalise development costs which would otherwise have been expensed. They further consider the impact of this on future earnings. To test out their hypothesis the authors utilise longitudinal data from 3,200 firm-year observations across 20 countries required to adopt IFRS in 2005. Controlling for firm and other country characteristics, a positive relationship between the amount of development cost capitalised and country level corruption was found, but this effect was tempered by the level of international exposure of the firms concerned. Overall, the authors demonstrate that pervasive country characteristics such as widespread fraud and corruption affects managers' decision making. Despite formal institutional regulatory and monitoring procedures being in place, the authors argue that, fraud and corruption pervades accounting choice raising concerns over the reliability of information within the firm's financial statements. These findings have wider policy implications. Policy makers need to consider the local cultural and institutional forms, which can permit systemic gaming to subvert rules by means that are technically legal, particularly when developing anti-corruption initiatives.

The final paper in this special issue considers accounting for crime in the neoliberal world. In this paper, Ala and Lapsley examine a recent European public sector reform that introduces calculative practices, which account for criminal activities such as drug trafficking and prostitution. The authors, drawing on extant literature, contextualise the emergence of "accounting for crime" policy within the waves of public sector accounting reforms, which have been stimulated by neoliberal ideology. The social construction of accounting for crime policy, as the result of the relentless march of neoliberal ideology, is analysed using the lenses of Gramscian Hegemony and Foucauldian Governmentality. Through examining national accounts, the authors reveal how accounting is complicit in the documentation and social construction of crime as a factor in increasing country GDP. Accounting, given its aptitude for creating visibilities as well as invisibilities, is ideally suited for such a controversial role. Their analysis demonstrates the commodification of human weakness, such as the supply and demand for drugs and prostitution, through the rational process of double entry records, the information from which is aimed at fulfilling the political and economic interests of precise 'historical blocs'. In this context, the centrality of accounting practice, as a neoliberal ideology, is made clear. The authors conclude that the current processes, aimed at accounting for criminal activity, do not reflect reality but rather transform it into something wholly more acceptable. These are important findings for both researchers and policy-makers. Accounting researchers and policy makers should dismiss the false pretence of accounting neutrality in the context of GDP (and elsewhere) and engage in a more fruitful collaboration aimed at the creation of a new social dimension of GDP's metrics which translate into increased social equity, justice and welfare for its citizens.

\section{Future Research}

Each of the above papers provide insights that expand our knowledge and understanding of the issues and practices around fraud and corruption. However, they present more questions than are answered and offer opportunities for more research.

A lot of emphasis is placed on governance and financial reporting with the aim of improving transparency and accountability. Although the objective of this is to ensure thorough 
monitoring and evaluation of financial activities by different stakeholders, interest in these reports may vary across and within subnational governments depending on their levels of socioeconomic development. Therefore, an important area of potential research is to examine whether differences in the extent of political competition and the efficiency of monitoring by bureaucrats have an impact on corruption.

With regards to SAIs, no single factor can explain why (or why not), they pursue particular strategies. The effectiveness of INTOSAI also appears to be limited. More qualitative and quantitative work is needed to facilitate greater understanding of how institutional pressures affect the work conducted by these organisations in the fight against fraud and corruption. Likewise, the link between auditing and corruption is also shown to be under researched. The exclusion of corruption from ISA240 for example, indicates a deficient standard and indicates a need for critical studies of the audit standard setting process that questions this rationale. Further studies could also be conducted to investigate ways in which institutional culture and norms can be modified via more stringent auditing to reduce fraud and corruption. In terms of the audit profession, investigation into incorporating corruption into the audit jurisdiction may provide insights into more effective means of encouraging the audit profession to accept more responsibility in detecting fraudulent and corrupt activity.

While accountability and transparency have been shown to be improved through greater financial and reporting disclosures, it is also evident that there is considerable potential to investigate both what encourages compliance amongst those that are subject to regulation and the reputational stigma associated with name and shame punishments. Additionally, managerial and accounting reforms aimed at increasing accountability and reducing corruption could consider the interactions between governance variables and multivariate regression analyses. Likewise, more investigation could be carried out to examine the potential joint effect of country-level societal trust and corruption on the market performance of capitalisers and expenses.

Our concluding paper demonstrates that we have much to learn from protectionist and jurisprudential practice, which utilise codes, guidelines, and calculative practices for quantifying, in monetary terms, the moral and existential damages stemming from illegal conduct of various types. The current practice of accounting for crime fails to consider or give prominence to the social costs (placing a price on pain and suffering) of such activity. More attention could therefore be given to investigating the human cost of illegal activity that leads to human suffering, slavery, inequality, wrongful deaths, as well as the lifetime costs associated with drug abuse.

The authors of this collection of papers are commended for their research efforts and contributions to enhancing our knowledge and understanding of the many issues that relate to the fight against fraud and corruption. We thank them for supporting both the Accounting, Society and the Environment workshop and this special issue of the British Accounting Review. We hope that you find this collection of papers as insightful and interesting as we have. 
Bardhan, P. (2002). Decentralization of governance and development. Journal of Economic Perspectives, 16(4), 185-205.

Borge, M. (1999). The role of supreme audit institutions (SAIs) in combating corruption. Transparency International. Available at: https://www.transparency.org/

Chan, L.K., Lakonishok, J. and Sougiannis, T. (2001). The stock market valuation of research and development expenditures. The Journal of Finance, 56(6), pp.2431-2456.

Cornell, B., Hsu, J., and Nanigian, D. (2017). Does past performance matter in investment manager selection? The Journal of Portfolio Management, 43 (4), 33-43.

Duqi, A., Jaafar, A. and Torluccio, G. (2015) Mispricing and risk of R\&D investment in European firms, The European Journal of Finance, 21:5, 444-465

Dye, K. (2007). Corruption and fraud detection by supreme audit institutions. In S. Anwar (Ed.), Performance Accountability and Combating Corruption, 303-322. Washington, DC, World Bank.

Farnham, D. and Horton, S. (1996). Managing Public and Private Organisations in Farnham, D. and Horton, S. (1996), Managing the New Public Services. 2nd Edition, London, Macmillan.

Hood, C. (1991). A public management for all seasons? Public Administration, 69(1), 3-19.

INTOSAI, (2013). ISSAI 5700 guidelines for the audit of corruption prevention in government agencies, Exposure Draft, Available at www.issai.org

Kayrak, M. (2008). Evolving challenges for supreme audit institutions in struggling with corruption. Journal of Financial Crime, 15 (10. 60-70.

Kaufmann, D., Kraay, A., and Mastruzzi, M., (2009). Governance matters VIII: Aggregate and individual governance indicators 1996-2008. The World Bank.

Parker, C. (2006). The "compliance" trap: The moral message in responsive regulatory enforcement. Law and Society Review, 40 (3), 591-622.

Pollitt, C. (1995). Justification by works or by faith? Evaluating the new public management. Evaluation, 1(2), 133-154.

Power, D., Lonie, A., and Lonie, R., (1991). Some UK evidence of stock market overreaction. British Accounting Review 23, 27-59.

Quah, J.S.T. (2001). Globalization and corruption control in Asian countries: The case for divergence. Public Management Review, 3(4), 453-470.

Salamon, L.M. (2002). The Tools of Government: A Guide to New Governance. Oxford, Oxford University Press.

Steinway, S. (2014). SEC "monetary penalties speak very loudly," but what do they say? A critical analysis of the SEC's new enforcement approach. Yale Law Journal. 124, 209-232.

Rothstein, B., \& Varraich, A. (2017). Making Sense of Corruption. Cambridge: Cambridge University Press. 
The World Economic Forum. (2017). Global Agenda. Available at: https://www.weforum.org/agenda/archive/corruption/

Wang, D., (2008). Are anomalies still anomalous? an examination of momentum strategies in four Financial markets. Available at: http://papers. ssrn. com.

Werden, G.J. (2009). Sanctioning cartel activity: Let the punishment fit the crime. European Competition Journal, 5(1), 19-36.

World Bank. (2001). Decentralization and subnational regional economics. Available at http://www1.worldbank.org/publicsector/decentralization/what.htm.

World Bank. (2017). Combating corruption. Available at: http://www.worldbank.org/en/topic/governance/brief/anti-corruption

von Maravic, P. 2007. Decentralized Corruption in Germany, Public Administration Quarterly, $30,(4), 440-78$. 